\section{Striding Ealge challenge surmounted}

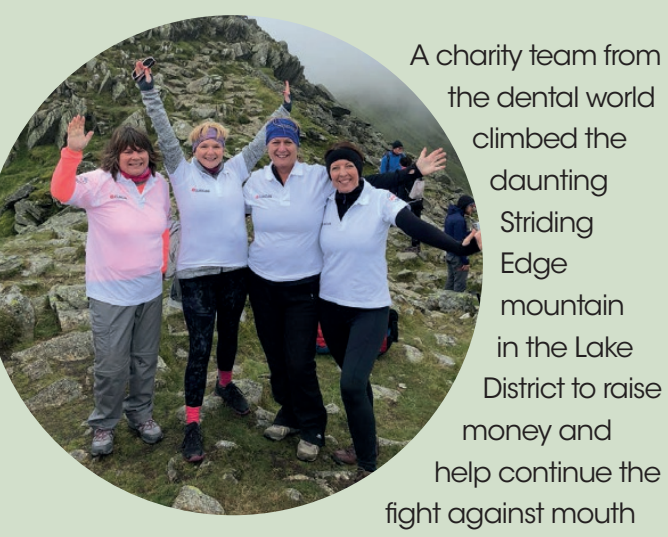

cancer in the UK.

Volunteers from Dental Health Spa,

the Oral Health Foundation, Swiss

Dental Academy, TePe and others, were supporting the Moveit4smiles charity. Funds raised by the team will be donated to Mouth Cancer Action and HPV Action.

Moveit4smiles spokesperson, hygienist Christina Chatfield, said of the challenge: 'At seven miles long, Striding Edge may not be the longest walk but it has incredibly high levels of exposure on narrow rocky ridges.'

All the walkers completed the walk in wet and windy conditions, reaching a height of 3000 feet. A portion of the money raised through the Striding Edge challenge will go towards educating teachers, parents and boys about the HPV vaccination.

To donate, visit www.dentalhealth. org/stridingedge or to get involved, find out more about walks in 2019, www. dentalhealth.org/moveit4smiles and sign up with your details.

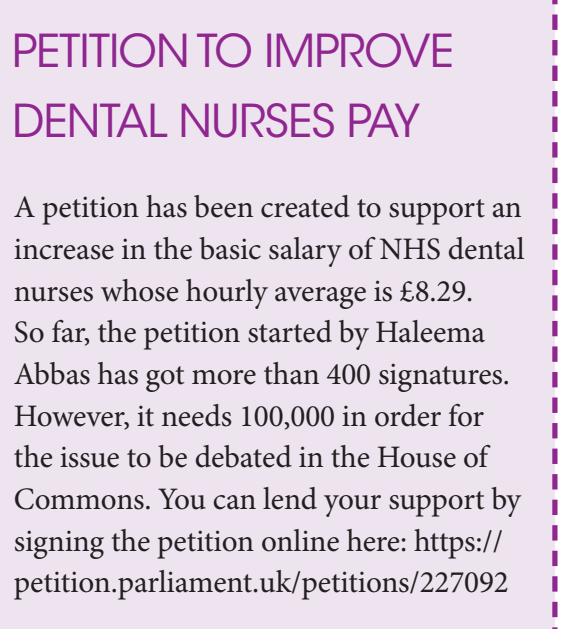

\title{
BREXIT-PROOF YOUR BUSINESS SAYS LAWYER
}

A Manchester solicitor is urging city dental practices to 'Brexit-proof' their businesses in the event the UK crashes out of the EU next March, or else consider selling up and maximising their business value.

'If higher prices are anticipated it would be wise to accumulate equipment and stock at current prices', says Helen Wong MBE, from Clarke Willmott LLP who specialises in advising the dental sector.

'At the moment equipment follows EU standards, but if the UK adopts its own guidelines there is a potential risk that many of the current or future apparatus or methodologies will not adhere to UK standards.

'For dental practices this could mean added costs to re-standardise, or in a worstcase scenario, they could find themselves in breach of the law solely because of a 'Hard Brexit' and the different standards being imposed.

'Practices should also be reviewing their private dental work fees and factor in the potential extra costs now, rather than to wait and see whether the UK crashes out of the European Union next March or not.'

Helen says she has seen a dramatic increase in Brexit-specific enquiries from dentists over the past two months and that the Clarke Willmott is supporting a number of practices to sell their businesses.

Clarke Willmott LLP is a national law firm with seven offices across the country, in Birmingham, Bristol, Cardiff, London, Manchester, Southampton and Taunton. For more information visit www. clarkewillmott.com

\section{UNIVERSAL WELCOME FOR HPV JAB FOR BOYS}

News that boys are to be offered a vaccination to protect against the Human Papilloma Virus (HPV) has been welcomed across the dental world. HPV causes about $5 \%$ of all cancers, specifically cervical, vulval and vaginal in women, penile in men, and anal and head and neck cancers in both sexes. HPV also causes genital warts and recurrent respiratory papillomatosis (RRP) in both men and women. The vaccination programme which was previously only available to girls, is due to start in September 2019.

The British Association of Dental Nurses said the decision taken by the Joint Committee on Vaccination and Immunisation (JCVI) to advise the Department of Health and Social Care that boys should be included in the national HPV vaccination programme was long overdue.

Approximately 400,000 boys each year have been left unprotected against HPV and the diseases it can cause since the vaccination programme for girls began in 2008. The government's vaccination advisory committee (JCVI) began its assessment of whether boys should also be vaccinated in 2013; decisions were promised but postponed until now.

HPV vaccination for boys is not only supported by the 51 organisations (of which BADN is one) of HPV Action but also by the BDA, BMA, Cancer Research UK and many individual clinicians; the clinical, ethical and equity arguments for gender-neutral vaccination are overwhelming. Approximately 20 other countries are already, or are planning to, vaccinate both boys and girls.

BADN President Hazel Coey said: 'I listened recently to a speaker at The Dentistry Show's Dental Nurse Forum, who explained how the HP Virus caused him to have cancer of the head and neck, changing his life forever; the horrors of the surgery as a result of the disease, the unspeakable life changes and the financial burden that he endured, leading him to thoughts of suicide - not to mention the costs to the NHS! As President of BADN, as well as a mother and grandmother of boys, I greatly welcome this decision to vaccinate our boys and eradicate this heartache.'

HPV Action Campaign Director Peter Baker said: 'The decision to vaccinate boys against HPV is great news for boys and their parents. It will also benefit those girls who for whatever reason have not been vaccinated against HPV. We have waited a long time for this change in policy and it is now imperative that there are no more delays and no more boys left at risk. HPV Action believes it is entirely realistic for boys throughout the UK to be vaccinated from September 2019. 